University of Nebraska - Lincoln

DigitalCommons@University of Nebraska - Lincoln

$3-1-2021$

\title{
Evaluation of lotions of botanical-based repellents against aedes aegypti (Diptera: Culicidae)
}

\author{
Whitney A. Qualls \\ Anastasia Mosquito Control District, quallsamcd@bellsouth.net \\ Rui De Xue \\ Anastasia Mosquito Control District \\ Muhammad Farooq \\ Anastasia Mosquito Control District \\ Steven T. Peper \\ Anastasia Mosquito Control District \\ Vindhya Aryaprema \\ Anastasia Mosquito Control District
}

See next page for additional authors

Follow this and additional works at: https://digitalcommons.unl.edu/usdaarsfacpub

Part of the Agriculture Commons

Qualls, Whitney A.; Xue, Rui De; Farooq, Muhammad; Peper, Steven T.; Aryaprema, Vindhya; Blore, Kai; Weaver, Richard; Autry, Dena; Talbalaghi, Asghar; Kenar, James; Cermak, Steven C.; and Zhu, Junwei J., "Evaluation of lotions of botanical-based repellents against aedes aegypti (Diptera: Culicidae)" (2021). Publications from USDA-ARS / UNL Faculty. 2509.

https://digitalcommons.unl.edu/usdaarsfacpub/2509

This Article is brought to you for free and open access by the U.S. Department of Agriculture: Agricultural Research Service, Lincoln, Nebraska at DigitalCommons@University of Nebraska - Lincoln. It has been accepted for inclusion in Publications from USDA-ARS / UNL Faculty by an authorized administrator of DigitalCommons@University of Nebraska - Lincoln. 


\section{Authors}

Whitney A. Qualls, Rui De Xue, Muhammad Farooq, Steven T. Peper, Vindhya Aryaprema, Kai Blore, Richard Weaver, Dena Autry, Asghar Talbalaghi, James Kenar, Steven C. Cermak, and Junwei J. Zhu 


\title{
Evaluation of Lotions of Botanical-Based Repellents Against Aedes aegypti (Diptera: Culicidae)
}

\author{
Whitney A. Qualls, ${ }^{1,6}$ Rui-De Xue, ${ }^{1}$ Muhammad Farooq, ${ }^{1}$ Steven T. Peper, ${ }^{1}$ \\ Vindhya Aryaprema, ${ }^{1}$ Kai Blore, ${ }^{1}$ Richard Weaver, ${ }^{1}$ Dena Autry, ${ }^{1}$ Asghar Talbalaghi, ${ }^{2}$ \\ James Kenar, ${ }^{3}$ Steven C. Cermak, ${ }^{4}$ and Junwei J. Zhu ${ }^{5}$
}

\begin{abstract}
'Anastasia Mosquito Control District, 120 EOC Drive, St. Augustine, FL 32092, ${ }^{2}$ Italian Mosquito Control Association (IMCA), Via Martiri delle Foibe, 2140068 San Lazzaro di Savena (B0), Italy, ${ }^{3}$ US Department of Agriculture, Agriculture Resaerch Service, National Center for Agriculture Utilization Research, Functional Foods Research Unit, Peoria, IL 61604, ${ }^{4}$ US Department of Agriculture, Agriculture Resaerch Service, National Center for Agriculture Utilization Research, Bio-Oils Research Unit, Peoria, IL 61604, ${ }^{5}$ US Department of Agriculture, Agricutlure Research Service, Agroecosystem Management Research Unit, University of Nebraska, Lincoln, NE 68583, and ${ }^{6}$ Corresponding author, e-mail: quallsamcd@bellsouth.net
\end{abstract}

Subject Editor: Monika Gulia-Nuss

Received 24 August 2020; Editorial decision 30 September 2020

\begin{abstract}
Thirteen botanical product repellent compounds such as 2-undecanone, capric, lauric, coconut fatty acids (and their methyl ester derivatives), and catnip oil were formulated in either Coppertone or Aroma Land lotions and evaluated against laboratory-reared Aedes aegypti L. (Diptera: Culicidae) mosquitoes. These formulations contained 7-15 wt/wt of the botanical repellent as the major active ingredient either pure or as mixtures. USDA standard repellent test cages were used to determine the complete protection time (CPT) of the different formulated repellents. Two of the evaluated formulations, a 7\% capric acid in Coppertone (CPT $2.7 \pm 0.6 \mathrm{~h}$ ) and $7 \%$ coconut fatty acids containing carrylic acid, capric acid, and lauric acid in Coppertone (CPT $2.3 \pm 2.0 \mathrm{~h}$ ), provided strong repellency against mosquitoes up to $3 \mathrm{~h}$, which was equivalent to the $(N, N$-diethyl- $m$-toluamide $)$ DEET control (CPT $2.7 \pm 0.6 \mathrm{~h}$ ). This work suggests future potential for these botanical product-based repellents as alternatives to commercial DEET-containing products.
\end{abstract}

Key words: repellent, essential oil, mosquito bite prevention, complete protection time

The use of mosquito repellents is one of the most effective ways to reduce nuisance and vector mosquito bites (Fradin 2001). The Centers for Disease Control and Prevention (CDC) has recommended six active ingredients (Barnard and Xue 2004) approved by the Environmental Protection Agency (EPA) to prevent mosquito bites, of which $N, N$-diethyl-m-toluamide (DEET) is the most effective (Yap et al. 1998; Thavara et al. 2001). Although DEET remains the gold standard, reports of its impact on human health have decreased public acceptance of the repellent (Ware and Whitacre 2004; CDC 2007).

The growing negative public perception to DEET and other synthetic chemicals (Isman 2006) in conjunction with FIFRA Section 25(b), which exempts registration of plant essential oil-based repellents, has led to a dramatic increase in available products claiming to prevent biting mosquitoes. There has been an overwhelming number of studies supporting the repellent and insecticidal properties of plant-derived essential oils (Sukumar et al. 1991;
Nerio et al. 2010; Lupi et al. 2013; Rehman et al. 2014). However, a major drawback to using plant-derived repellents is the limited residual or protection time offered by these products compared with DEET (Rehman et al. 2014). Thus, there is a need to develop plantbased active ingredients that offer similar protection time and efficacy as the current EPA approved active ingredients.

Recently, medium-chain-length fatty acids, including carrylic acid, capric acid, and lauric acid, derived from coconut oil have been shown to exhibit repellent activity against various biting arthropods (Zhu et al. 2018). Repellency by these fatty acids against ticks, bed bugs, and biting flies was found to be stronger than DEET while providing a longer residual effect. Similar evidence for their repellency against mosquitoes suggests that these compounds merit further research. Catnip oil is another viable candidate to investigate as it is considered one of the strongest biting fly repellents (Zhu et al. 2009), exhibiting similar repellency as DEET against mosquitoes (Reichert et al. 2019). The findings presented herein investigate 
the complete protection time (CPT), the time between exposure of the treated arm to the time when the first mosquito landed on or bit a treated arm, of 13 mixtures containing one or more botanical product repellent candidates formulated into two carrier skin protection lotions.

\section{Materials and Methods}

Thirteen repellent formulations were prepared by the United States Department of Agriculture/Agriculture Research Service (USDA/ ARS) and sent to Anastasia Mosquito Control District (AMCD), St. Augustine, FL, for testing. The formulated products (Table 1) were prepared using either Coppertone (CP) or Aroma Land (AL) lotions as the carrier. The botanical repellents, 2 -undecanone, capric $\left(\mathrm{C}_{10}\right)$, lauric $\left(\mathrm{C}_{12}\right)$, coconut fatty acids and each of their corresponding methyl esters, and catnip oil, were added either in pure form or as a (1:1) mixture to their respective carrier lotion.

A 6.65\% DEET control (Cutter Skinsations Insect Repellent, St. Louis, MO) was used as the positive control. The two carrier lotions, $\mathrm{CP}$ and AL, were used as negative controls and were provided by USDA/ARS. All formulated materials were received as label encoded samples (A through O), so the evaluation could be conducted as a blind study.

Aroma Land Hand and Body Lotion (Unscented) was purchased from Aromaland Inc. (Santa Fe, NM). Coppertone Tanning Sunscreen Lotion, SPF 8, Water Resistant ( $80 \mathrm{~min}$ ) was purchased from Bayer HealthCare LLC (Whippany, NJ). Boron trifluoride diethyl etherate and 2-undecanone (99\%) was purchased from SigmaAldrich Co. (St. Louis, MO). Capric acid (96\%) was purchased from Acros Organics (Morris, NJ). Coconut Fatty Acid 745 Food grade Kosher was purchased from Acme Hardesty (Blue Bell, PA). Lauric acid $(97 \%)$ was purchased from Pfaltz \& Bauer (Waterbury, CT). Catnip essential oil was purchased from Bramble Berry (Bellingham, WA). Hexanes, ethyl acetate, sodium sulfate, sodium chloride, and sodium phosphate monobasic monohydrate were purchased from Fisher Scientific Co. (Fairlawn, NJ). Methanol was obtained from EMD Millipore Co. (Billerica, MA). Filter paper was obtained from Whatman (Clifton, NJ).
Acid-catalyzed esterification reactions were conducted in a 1-liter round bottom flask. A solution of boron trifluoride diethyl etherate $(0.4 \mathrm{M}, 9.45 \mathrm{ml})$ in methanol $(190.55 \mathrm{ml})$ was added to $100.00 \mathrm{~g}$ of the starting fatty acid (e.g., capric acid, lauric acid, or coconut fatty acid). The reaction was heated to reflux with a cold condenser. After $24 \mathrm{~h}$, the flask contents were allowed to cool to room temperature and transferred to a separatory funnel followed by the addition of $50 \mathrm{ml}$ of a 1:1 ethyl acetate:hexane solution. The $\mathrm{pH}$ of the solution was then adjusted to 5.0-6.0 using distilled water and a final wash with a sodium phosphate buffer $\left(\mathrm{NaH}_{2} \mathrm{PO}_{4}, \mathrm{pH} 5,519 \mathrm{~g}\right.$ in 4-liter $\mathrm{H}_{2} \mathrm{O}$ ). The organic layer was then washed with a saturated sodium chloride solution, dried over sodium sulfate, and filtered with Whatman \#54 filter paper. All reactions were concentrated in vacuo via Kugelrohr distillation $(0.013-0.067 \mathrm{kPa})$ up to $100-110^{\circ} \mathrm{C}$ to yield the purified, colorless fatty acid methyl ester distillates. The final product was then filtered through Whatman \#54 paper.

Samples were prepared by weighing each botanical product repellent into a tared 4 or 8 oz Qorpak glass jar depending on the final sample size desired. The corresponding amount and type of carrier lotion was then added to the jar. The samples were then vigorously mixed using a Cat Scientific X120 Handheld Homogenizer Drive with a T10 Dispersing Tool fitted with a V Type Generator. Mixing time varied depending on sample size, $2 \mathrm{oz}$ samples were mixed from 60 to $70 \mathrm{~s}$, whereas larger $5 \mathrm{oz}$ samples were mixed from 120 to 135 s. The compounds that were solid at room temperature, i.e., capric acid, coco fatty acid, and the capric/coco fatty acid mixture were gently heated on a steam bath before weighing and then again immediately before mixing. The homogenizer was wiped clean between each sample and then rinsed with acetone. The homogenizer was finally submerged in a clean jar of acetone and turned on to remove any residual products from the dispersing tool. The remaining acetone was then blown off with the use of an air hose.

USDA standard repellent test procedures modified from EPA (2009) methods were followed. Mosquito cages $(35.5 \times 38.1 \times 45.7 \mathrm{~cm})$ with laboratory-reared Aedes aegypti L. (Diptera: Culicidae) were positioned in a large room, at $22-23^{\circ} \mathrm{C}$ with ambient relative humidity of $60 \%$. Mosquitoes were reared at AMCD insectary with conditions maintained at $26.6 \pm 1{ }^{\circ} \mathrm{C}, 70.0 \pm 10 \%$ relative humidity,

Table 1. Repellent formulation including active ingredient(s) and complete protection time

\begin{tabular}{|c|c|c|c|c|c|}
\hline Sample code & Active ingredient & Formulation & Percentage ( $\%$ wt $)$ & $\mathrm{CPT}(\mathrm{h}) \pm \mathrm{SD}$ & Range (h) \\
\hline A & 2-Undecanone & Coppertone & 15 & $0 a$ & 0 \\
\hline B & 2-Undecanone & Aroma Land Lotion & 15 & $0.3 \pm 0.6 a$ & $0-1$ \\
\hline $\mathrm{C}$ & C10 fatty acid & Coppertone & 7 & $2.7 \pm 0.6$ & $2-3$ \\
\hline $\mathrm{D}$ & Coconut fatty acids & Coppertone & 7 & $2.3 \pm 2.0$ & $0-5$ \\
\hline $\mathrm{E}$ & C10 fatty acid/coconut fatty acids & Coppertone & 7 & $2 \pm 0$ & 2 \\
\hline $\mathrm{F}$ & C10 fatty acid methyl ester & Aroma Land Lotion & 7 & $0.6 \pm 1.2 a$ & $0-2$ \\
\hline G & C10 fatty acid methyl ester & Coppertone & 7 & $0 a$ & 0 \\
\hline $\mathrm{H}$ & C12 fatty acid methyl ester & Aroma Land Lotion & 7 & $0 a$ & 0 \\
\hline I & C12 fatty acid methyl ester & Coppertone & 7 & $0 a$ & 0 \\
\hline $\mathrm{J}$ & Coconut fatty acid methyl esters & Coppertone & 7 & $0 a$ & 0 \\
\hline $\mathrm{K}$ & Coconut fatty acid methyl esters & Aroma Land Lotion & 7 & $0 a$ & 0 \\
\hline $\mathrm{L}$ & Control & Coppertone & 0 & $0 a$ & 0 \\
\hline $\mathrm{M}$ & Control & Aroma Land Lotion & 0 & $0 a$ & 0 \\
\hline $\mathrm{N}$ & Catnip & Coppertone & 10 & $0.6 \pm 1.2 a$ & $0-2$ \\
\hline $\mathrm{O}$ & Catnip & Aroma Land Lotion & 10 & $2 \pm 0$ & 2 \\
\hline $\begin{array}{l}\text { Cutter Skinsations Insect } \\
\text { Repellent }\end{array}$ & DEET & Liquid & 6.65 & $2.7 \pm 0.6$ & $2-3$ \\
\hline
\end{tabular}

CPT, complete protection time; DEET, $N, N$-diethyl-m-toluamide.

${ }^{a}$ The mean CPT of the repellent formulations was significantly different $(P<0.05$ by analysis of variance and Tukey's test). 
and a 14:10 h (L:D) photoperiod. Cages were placed on individual tables separated at least $5 \mathrm{~m}$ apart from one another.

Testing was conducted on eight AMCD employee volunteers, five males and three females ranging in age between 36 and 65 and 31-58, respectively, all of whom provided written informed consent using the AMCD consent form. Each repellent formulation $(2 \mathrm{ml})$ was applied to the forearm of a volunteer and allowed to dry for $1 \mathrm{~h}$ prior to evaluation. Each volunteer received different treatments on each arm. During the evaluation volunteers inserted their left arm into a cage with 200 starved, 5- to 7-d-old female Ae. aegypti for a 3-min exposure period. Following the first arm, a 1-min reset period was conducted, and then the right arm was inserted into the cage for 3 min. Participants wore thick garden gloves (ACE Hardware) to protect their hands. The number of mosquitoes landing and probing on the exposed forearm was counted and recorded during the exposure. The test was completed when the mosquitoes successfully probed or after $3 \mathrm{~min}$ if no mosquitoes probed. If no probing occurred after the $3 \mathrm{~min}$, the participants would repeat the procedure after $1 \mathrm{~h}$. These tests were repeated three times on different days, and each formulation was rotated, so that a single participant never had the same repellent formulation. The three separate replications were averaged, and the CPT was calculated. CPT was defined as the time from application of the repellent/control to the time the first mosquito landed on or bit the repellent/control-treated arm.

One-way analysis of variance followed by Tukey's test was used to compare the mean CPT for the tested repellents and controls. A $P$-value of less than 0.05 was considered to indicate statistical significance.

\section{Results}

DEET $(6.65 \%)$ provided $2.5 \mathrm{~h}$ of CPT. There was a statistically significant difference in CPT compared with DEET ( $\mathrm{df}=15, P=0.007)$. A Tukey's post hoc test revealed four formulations that provided no statistically significant difference in the CPT compared with DEET: $10 \%$ catnip oil in $\mathrm{AL}, 7 \% \mathrm{C}_{10}$ fatty acid, $7 \% \mathrm{C}_{10}$ fatty acid/coconut fatty acid (1:1) in CP, and the $7 \%$ coconut fatty acid in CP. Table 1 lists the CPT times of these repellent formulations. A CPT just under $1 \mathrm{~h}$ was provided by the $15 \%$-undecanone in AL lotion, $10 \%$ catnip in $\mathrm{CP}$, and $7 \% \mathrm{C}_{10}$ fatty acid methyl ester in AL lotion. The $\mathrm{CP}$, $\mathrm{AL}, 7 \% \mathrm{C}_{10}$ fatty acid methyl ester in CP, 7\% C12 fatty acid methyl ester in $\mathrm{AL}, 7 \% \mathrm{C}_{12}$ fatty acid methyl ester in $\mathrm{CP}, 7 \%$ coconut fatty acid methyl ester in $\mathrm{AL}$, and $7 \%$ coconut fatty acid methyl esters in $\mathrm{CP}$ provided no CPT.

\section{Discussion}

The findings of this study demonstrate that both the coconut fatty acids and $\mathrm{C}_{10}$ fatty acid formulated in $\mathrm{CP}$ resulted in efficacy with the same CPT as the commercial repellent product containing the $6.65 \%$ DEET. Other formulations combining mixtures of coconut fatty acids and the medium-chain-length fatty acids showed promising protection times when compared with the control. Overall, our findings support a previous study that demonstrated equal repellency between the coconut fatty acids and DEET against Ae. aegypti (Zhu et al. 2018). Additionally, this study corroborated previous findings showing catnip oil as an effective plant-based repellent and comparable to DEET against Ae. aegypti (Reichert et al. 2019). Although, the $10 \%$ catnip oil in AL provided 30 min less CPT time compared with DEET in the current study.
Interestingly, the $15 \%$ 2-undecanone in $\mathrm{CP}$ and $\mathrm{AL}$ resulted in no and 0.3 (h) CPT, respectively. The EPA list 2-undecanone as an approved repellent for mosquito bit prevention, but the literature has few reports and those reports demonstrate limited protection (Patel et al. 2016). The results presented here suggest that 2-undecanone offers limited protection from mosquito bites and the botanical products formulated with coconut fatty acids and $\mathrm{C}_{10}$ fatty acid would be a more suitable alternative to 2-undecanone.

Both coconut oil and its corresponding medium-chain-length fatty acids are 'generally recognized as safe' (GRAS; FDA 2018). Medium-chain-length fatty acids such as capric acid are readily available, inexpensive commodities, and widely used in the food and cosmetics industries (Libert 1987; Gervajio 2005). These characteristics make coconut fatty acids desirable materials for repellent development.

It should be noted that the Coppertone product label suggests reapplication every $80 \mathrm{~min}$. Active coconut fatty acids and their methyl ester repellent compounds are not highly volatile and contain no double bonds and are expected to be thermal and oxidatively stable as a formulated product. Although 2-undecanone is also expected to be thermally and oxidatively stable, it has a high vapor pressure, so packaging controls would be needed to prevent its evaporation when formulated with the lotions. In addition to volatility, catnip oil is also susceptible to degradation due to UV, heat, and oxygen (Patience et al. 2018), and therefore would require additional packaging controls to reduce its degradation and loss. Future evaluations of botanical repellent compounds should be formulated with lotions offering periods of control that match the duration of the repellent activity and with the additional packaging controls necessary to stabilize the active ingredient.

It has been demonstrated that fatty acids derived from coconut oil present stronger repellency against several blood-sucking insects, compared with DEET (Zhu et al. 2018). Further development of formulations containing coconut fatty acids is needed to determine the role coconut fatty acids play in mosquito bite prevention with these current findings laying the initial framework to determine which medium-chain-length fatty acid provides the longest CPT against mosquitoes. Further research to determine the optimal fatty acid concentration of the four stand out formulations is needed to optimize them as a mosquito repellent. The GRAS status of the coconut fatty acids should increase their acceptance as a mosquito repellent by consumers and public health professionals.

\section{Acknowledgments}

This is a research report only and specific mention of any commercial products does not imply endorsement by the Anastasia Mosquito Control District. Mention of trade names or commercial products in this publication is solely for the purpose of providing specific information and does not imply recommendation or endorsement by the US Department of Agriculture. USDA is an equal opportunity provider and employer.

\section{References Cited}

Barnard, D. R., and R. D. Xue. 2004. Laboratory evaluation of mosquito repellents against Aedes albopictus, Culex nigripalpus, and Ochierotatus triseriatus (Diptera: Culicidae). J. Med. Entomol. 41: 726-730.

Fradin, M. S. 2001. Protection from blood-feeding arthropods, pp. 754-768. In P. S. Auerback (ed.), Wilderness medicine, 4th ed. Mosby, St. Louis.

Gervajio, G. C. 2005. Fatty acids and derivatives from coconut oil. John Wiley \& Sons, Inc. 
Isman, M. B. 2006. Botanical insecticides, deterrents, and repellents in modern agriculture and an increasingly regulated world. Annu. Rev. Entomol. 51: 45-66.

Libert, M. A. 1987. Final report on the safety assessment of oleic acid, lauric acid, palmitic acid, myristic acid, and stearic acid. J. Am. Coll. Toxicol. 6: 321-401.

Lupi, E., C. Hatz, and P. Schlagenhauf. 2013. The efficacy of repellents against Aedes, Anopheles, Culex and Ixodes spp. - a literature review. Travel Med. Infect. Dis. 11: 374-411.

Nerio, L. S., J. Olivero-Verbel, and E. Stashenko. 2010. Repellent activity of essential oils: a review. Bioresour. Technol. 101: 372-378.

Patel, R. V., K. M. Shaeer, P. Patel, A. Garmaza, K. Wiangkham, R. B. Franks, O. Pane, and N. W. Carris. 2016. EPA-registered repellents for mosquitoes transmitting emerging viral disease. Pharmacotherapy 36: 1272-1280.

Patience, G. S., G. Karirekinyana, F. Galli, N. A. Patience, C. Kubwabo, G. Collin, J. C. Bizimana, and D. C. Boffito. 2018. Sustainable manufacture of insect repellents derived from Nepeta cataria. Sci. Rep. 8: 2235.

Rehman, J. U., A. Ali, and I. A. Khan. 2014. Plant based products: use and development as repellents against mosquitoes: a review. Fitoterapia 95: $65-74$.

Reichert, W., J. Ejercito, T. Guda, X. Dong, Q. Wu, A. Ray, and J. E. Simon. 2019. Repellency assessment of Nepeta cataria essential oils and isolated Nepetalactones on Aedes aegypti. Sci. Rep. 9: 1524

Sukumar, K., M. J. Perich, and L. R. Boobar. 1991. Botanical derivates in mosquito control: a review. J. Am. Mosq. Control Assoc. 7: 210-237.
Thavara, U., A. Tawatsin, J. Chompoosri, W. Suwonkerd, U. R. Chansang, and P. Asavadachanukorn. 2001. Laboratory and field evaluations of the insect repellent 3535 (ethyl butylacetylaminopropionate) and DEET against mosquito vectors in Thailand. J. Am. Mosq. Control Assoc. 17: 190-195.

United States Centers for Disease Control and Prevention (CDC). 2007. Insect repellent use and safety. West Nile Virus.

United States Environmental Protection Agency (EPA). 2009. OPPTS 810.3700: insect repellents to be applied to human skin. (http://www.regulations.gov/\#!documentDetail;D=EPA-HQ-OPPT-2009-0150-0011).

United State Food and Drug Administration (FDA). 2018. GRAS Substances (SCOGS) Database. (https://www.fda.gov/food/ generally-recognized-safe-gras/gras-substances-scogs-database).

Ware, G. W., and D. M. Whitacre. 2004. The pesticide book. 6th ed. Meister Media Worldwide, Willoughby, OH.

Yap, H. H., K. Jahangir, A. S. Chong, C. R. Adanan, N. L. Chong, Y. A. Malik, and B. Rohaizat. 1998. Field efficacy of a new repellent, KBR 3023, against Aedes albopictus (SKUSE) and Culex quinquefasciatus (Say) in a tropical environment. J. Vector Ecol. 23: 62-68.

Zhu, J. J., X. P. Zeng, D. Berkebile, H. J. Du, Y. Tong, and K. Qian. 2009. Efficacy and safety of catnip (Nepeta cataria) as a novel filth fly repellent. Med. Vet. Entomol. 23: 209-216.

Zhu, J. J., S. C. Cermak, J. A. Kenar, G. Brewer, K. F. Haynes, D. Boxler, P. D. Baker, D. Wang, C. Wang, A. Y. Li, et al. 2018. Better than DEET repellent compounds derived from coconut oil. Sci. Rep. 8: 14053. 